\title{
Low serum vitamin $D$ concentrations are associated with obese but not lean NAFLD: a cross-sectional study
}

\author{
Qinqiu Wang ${ }^{1}$, Xiaoying Shi ${ }^{1}$, Jinghua Wang ${ }^{1}$, Juanwen Zhang $^{2}$ and Chengfu Xu ${ }^{1 *}$ (D)
}

\begin{abstract}
Background: A low serum vitamin D concentration has been reported to be associated with an increased risk of non-alcoholic fatty liver disease (NAFLD); however, whether lean or obese individuals show a similar association between vitamin D and NAFLD remains speculative. This study aimed to explore the relationship between serum vitamin D concentration and NAFLD in lean and obese Chinese adults.

Methods: This cross-sectional study included 2538 participants (1360 men and 1178 women) who underwent health checkups at the First Affiliated Hospital, Zhejiang University School of Medicine in 2019. NAFLD was diagnosed by liver ultrasound excluding other causes. The association of serum vitamin D concentration with NAFL D was analyzed in lean and obese participants.

Results: The overall prevalence of NAFLD was $33.61 \%$ (13.10\% in lean and $53.32 \%$ in obese) in this study population. The serum vitamin D levels of obese NAFLD patients were lower than those of obese NAFLD-free controls. However, the serum vitamin D levels of lean NAFLD patients were comparable to those of lean NAFLDfree controls. Serum vitamin D level was negatively correlated with the prevalence of NAFLD in obese but not lean participants. Serum vitamin D level was independently associated with the risk of NAFLD in obese participants, with an adjusted odds ratio $(95 \% \mathrm{Cl})$ of $0.987(0.981-0.993)$. However, serum vitamin D level was not related to the risk of NAFLD in lean participants.
\end{abstract}

Conclusions: A low serum vitamin D level is associated with NAFLD in obese but not lean participants.

Keywords: Non-alcoholic fatty liver disease, Vitamin D, Obesity, Body mass index, Cross-sectional study

\section{Background}

Non-alcoholic fatty liver disease (NAFLD) is defined as hepatic steatosis when liver lipid deposition is not secondarily caused by heavy drinking or other known etiologies with or without inflammation and fibrosis [1]. NAFLD is currently one of the world's most common chronic liver diseases, affecting approximately $29.2 \%$ of adults in China [2]. NAFLD can lead to simple steatosis,

\footnotetext{
* Correspondence: xiaofu@zju.edu.cn

'Department of Gastroenterology, the First Affiliated Hospital, Zhejiang University School of Medicine, 79 Qingchun Road, Hangzhou 310003, China Full list of author information is available at the end of the article
}

steatohepatitis, cirrhosis, and even hepatocellular carcinoma [3, 4]. Patients with NAFLD have increased risks of cardiovascular disease, stroke, type 2 diabetes, and extrahepatic malignancies [5-8]. The high prevalence and serious clinical harms of NAFLD have made it a global research hotspot in recent years [9].

Obesity is closely related to NAFLD; the prevalence of NAFLD is higher in obese individuals than in lean individuals, and the accompanying risks are greater [10]. Recently, though, many studies have shown that non-obese people also have a high prevalence of NAFLD [11, 12]. We have previously reported that in China, the 
prevalence of NAFLD in the non-obese population is 7.3 , and $8.9 \%$ of non-obese adults developed NAFLD during a 5-year follow-up [13]. Compared with obese NAFLD patients, lean NAFLD patients are usually asymptomatic and difficult to diagnose, but in fact, they also have severe liver histological necrotizing inflammation and high mortality [14]. NAFLD in the non-obese population may also cause significant health problems [15]. Therefore, the identification, diagnosis, and treatment of non-obese NAFLD is very important.

The risk factors for non-obese NAFLD remain unclear. Some previous cross-sectional studies showed that vitamin D deficiency was associated with an increased risk of NAFLD, and vitamin D levels were negatively associated with the severity of NAFLD [16, 17]. Several prospective studies also pointed out that serum vitamin $\mathrm{D}$ deficiency was accompanied by an increased risk of incident NAFLD [18-21]. Our recent study showed that serum vitamin D levels in high-fat diet-fed mice were significantly decreased, and vitamin D supplementation ameliorated high-fat dietinduced hepatic steatosis in mice [22]. Vitamin D supplementation could also improve hepatic steatosis in patients with NAFLD [23, 24]. However, it is unclear whether obesity affects the correlation between vitamin $\mathrm{D}$ concentration and NAFLD, and whether serum vitamin D concentration is related to NAFLD in lean individuals.

In this study, we aimed to explore the correlation between serum vitamin D concentration and NAFLD in obese and lean Chinese adults.

\section{Methods \\ Participants}

We enrolled adults who underwent health checkups at the First Affiliated Hospital, Zhejiang University School of Medicine in 2019 as participants in our cross-sectional study. The analysis included participants with complete anthropometric and biochemical data records (including serum vitamin D concentrations) and liver ultrasound results. We excluded the following participants: (i) participants with incomplete anthropometric and biochemical data; (ii) men with alcohol consumption $>210 \mathrm{~g} /$ week and women with alcohol consumption > $140 \mathrm{~g} /$ week; (iii) participants with other chronic liver diseases caused by autoimmune hepatitis or viral hepatitis; and (iv) participants who use hepatotoxic drugs (such as sulfonamide and azithromycin).

The personal information of all of the participants was anonymous. The study was approved by the Ethical Committee of the First Affiliated Hospital, Zhejiang University School of Medicine.

\section{Clinical examinations}

Clinical examinations included questionnaires, medical history, anthropometric measurements, and biochemical analysis. During the examination, the physician recorded the medical history (including previous diseases and drug prescriptions) and drinking frequency and amount. The smoking history was also recorded and distinguished as yes or no.

The anthropometric measurements were performed as previously described, including body weight, standing height, waist circumference, and blood pressure [25, 26]. Weight and height were measured when the patient was wearing light clothing and no shoes. Waist circumference was measured after the patient exhaled, with the tape measure placed between the lowest rib and the upper edge of the iliac crest. Blood pressure was measured after resting for $5 \mathrm{~min}$. Body mass index (BMI) was calculated as the weight $(\mathrm{kg})$ divided by height $(\mathrm{m})$ squared.

Fasting blood samples were taken from the anterior cubital vein and were used for biochemical analysis. Measurements included liver enzymes, blood lipids, glucose, and uric acid. All of the biochemical values were measured by a Hitachi 7600 clinical analyzer (Hitachi, Tokyo, Japan) using standard methods. Serum 25hydroxyvitamin $\mathrm{D}$ levels were measured with the electro-chemiluminescence immunoassay (ECLIA) platform using the Roche cobas e602 analyzer (Roche Diagnostics $\mathrm{GmbH}$, Germany).

\section{Diagnostic criteria and definitions}

Lean was defined as $B M I<24 \mathrm{~kg} / \mathrm{m}^{2}$, and obesity was defined as BMI $\geq 24 \mathrm{~kg} / \mathrm{m}^{2}$ [27]. The quartiles of serum vitamin $\mathrm{D}$ levels were defined as follows: quartile 1, vita$\min \mathrm{D}<45.5 \mathrm{nmol} / \mathrm{L} ;$ quartile $2, \quad 45.5-59.5 \mathrm{nmol} / \mathrm{L}$; quartile $3,59.6-74.2 \mathrm{nmol} / \mathrm{L}$; and quartile 4 , vitamin $\mathrm{D} \geq$ $74.3 \mathrm{nmol} / \mathrm{L}$. Vitamin D deficiency was defined as vita$\min \mathrm{D}<50.0 \mathrm{nmol} / \mathrm{L}$; vitamin $\mathrm{D}$ insufficiency as 50.0 $74.9 \mathrm{nmol} / \mathrm{L}$; and vitamin $\mathrm{D}$ sufficiency as vitamin $\mathrm{D} \geq$ $75.0 \mathrm{nmol} / \mathrm{L}$ [28] . Central obesity was defined as waist circumference $\geq 90 \mathrm{~cm}$ in males and $\geq 80 \mathrm{~cm}$ in females according to the International Diabetes Federation cutoffs for Chinese adults [29].

\section{Diagnosis of NAFLD}

An abdominal ultrasound examination was performed by experienced ultrasonographers using the Toshiba Nemio 20 ultrasound system (Toshiba, Tokyo, Japan) with a $3.5 \mathrm{MHz}$ probe. The ultrasonographers were unaware of the study's purpose and laboratory values. Fatty liver disease was diagnosed according to the standards of the Chinese Liver Disease Association, wherein the diagnosis requires the presence of significant hepatic steatosis confirmed by imaging or histological examination, in 
the absence of other causes for fatty liver diseases such as overconsumption of alcohol [30].

\section{Statistical analysis}

The statistical analysis was performed by SPSS (SPSS, Chicago, IL) for Mac version 18.0. Continuous variables were presented as mean $\pm S D$ or median and interquartile range (IQR). Student's $t$ test was applied to compare continuous data, and the $\chi^{2}$ test was applied to compare categorical variables. The Cochran-Armitage trend test showed the trend of prevalence. Logistic regression analysis was used to identify possible risk factors for NAFL D. $P<0.05$ (two-tailed test) was considered to be statistically significant.

\section{Results}

Clinical characteristics of the study population

A total of 2538 participants (1360 men and 1178 women) were included in this study, and 853 (33.61\%) had NAFLD. The prevalence of NAFLD was $13.10 \%$ in lean participants $\left(B M I<24 \mathrm{~kg} / \mathrm{m}^{2}\right)$ and $53.32 \%$ in obese participants $\left(\mathrm{BMI} \geq 24 \mathrm{~kg} / \mathrm{m}^{2}\right)$. Comparing clinical characteristics based on NAFLD status (Table 1), we found that both lean and obese NAFLD patients had higher BMI, larger waist circumference, higher systolic and diastolic blood pressure, and elevated serum levels of alanine aminotransferase, $\gamma$-glutamyl transpeptidase, triglyceride, uric acid, and fasting glucose, but lower serum HDL-cholesterol levels than corresponding controls. In addition, the vitamin D levels of obese NAFLD patients were lower than those of obese NAFLD-free controls $\quad(59.03 \pm 19.46 \mathrm{nmol} / \mathrm{L}$ versus $63.56 \pm 22.09$ $\mathrm{nmol} / \mathrm{L}, P<0.001)$, but this was not observed in lean participants (Table 1 ).

\section{Association of serum vitamin D level with the prevalence of NAFLD}

We classified all of the participants into quartiles by their serum vitamin D levels and analyzed the association of vitamin $\mathrm{D}$ quartiles with the prevalence of NAFLD. We found that serum vitamin D quartiles were negatively associated with the prevalence of NAFLD in obese participants (Table 2). The prevalence of NAFLD was 56.54, 59.77, 52.15, and $44.51 \%$ in the first, second, third, and fourth quartiles of serum vitamin $D$ in obese participants, respectively ( $P$ for trend $<0.01$; Table 2 ). However, serum vitamin $D$ quartiles were not associated with the prevalence of NAFLD in lean participants (Table 2).

We also divided all of the participants into three groups according to their vitamin D adequacy status and analyzed the association of vitamin D adequacy status with the prevalence of NAFLD in lean and obese participants. In the obese group, we found that participants with vitamin D deficiency had the highest prevalence of NAFLD (57.60\%), followed by those with vitamin D insufficiency (55.73\%), and then those with vitamin D sufficiency $(43.23 \%$ ) ( $P$ for trend < 0.001 ; Table 3 ). In the lean group, the prevalence of NAFLD was comparable among participants with vitamin D deficiency and those with vitamin D sufficiency $(11.14 \%$ versus $10.89 \%$, Table 3$)$.

Table 1 Clinical characteristics of the study population according to obese and NAFLD categories

\begin{tabular}{|c|c|c|c|c|c|c|c|}
\hline \multirow[t]{2}{*}{ Variables } & \multirow{2}{*}{$\begin{array}{l}\text { Overall }(n= \\
2538)\end{array}$} & \multicolumn{3}{|c|}{ Lean participants } & \multicolumn{3}{|c|}{ Obese participants } \\
\hline & & $\begin{array}{l}\text { NAFLD } \\
(n=163)\end{array}$ & $\begin{array}{l}\text { Without NAFLD } \\
(n=1081)\end{array}$ & $P$ value & $\begin{array}{l}\text { NAFLD } \\
(n=690)\end{array}$ & $\begin{array}{l}\text { Without NAFLD } \\
(n=604)\end{array}$ & $P$ value \\
\hline Age (year) & $54.08(6.85)$ & $54.84(6.59)$ & $53.81(6.96)$ & 0.078 & $54.23(6.60)$ & $54.18(6.99)$ & 0.901 \\
\hline Male gender (\%) & $1360(53.39)$ & $86(52.76)$ & $430(39.78)$ & 0.002 & 485 (70.29) & $359(59.44)$ & $<0.001$ \\
\hline Body mass index $\left(\mathrm{kg} / \mathrm{m}^{2}\right)$ & $24.22(2.96)$ & $22.77(1.14)$ & $21.71(1.54)$ & $<0.001$ & $27.09(2.18)$ & $25.83(1.73)$ & $<0.001$ \\
\hline Waist circumference (cm) & $85.13(8.67)$ & $83.34(5.12)$ & $78.66(6.12)$ & $<0.001$ & $92.88(6.39)$ & $88.35(6.37)$ & $<0.001$ \\
\hline Systolic blood pressure (mmHg) & $127.93(18.38)$ & $127.64(16.86)$ & $122.77(18.51)$ & 0.002 & $134.37(17.41)$ & $129.88(16.89)$ & $<0.001$ \\
\hline Diastolic blood pressure $(\mathrm{mmHg})$ & $78.37(11.56)$ & $78.08(9.98)$ & $74.77(11.26)$ & $<0.001$ & $82.96(10.72)$ & $79.65(11.34)$ & $<0.001$ \\
\hline Alanine aminotransferase (U/L) & $23.21(19.06)$ & $28.64(45.74)$ & $18.24(12.69)$ & 0.004 & $30.78(16.61)$ & $22.00(15.60)$ & $<0.001$ \\
\hline Y-Glutamyl Transpeptidase (U/L) & $29.90(31.84)$ & $35.50(35.39)$ & $23.00(31.34)$ & $<0.001$ & $40.49(32.64)$ & $28.64(26.98)$ & $<0.001$ \\
\hline Triglyceride (mmol/L) & $1.63(1.14)$ & $2.02(1.16)$ & $1.26(0.82)$ & $<0.001$ & $2.17(1.43)$ & $1.54(0.95)$ & $<0.001$ \\
\hline HDL-cholesterol (mmol/L) & $1.22(0.34)$ & $1.12(0.26)$ & $1.36(0.36)$ & $<0.001$ & $1.04(0.25)$ & $1.19(0.28)$ & $<0.001$ \\
\hline LDL-cholesterol (mmol/L) & $2.75(0.72)$ & $2.83(0.79)$ & $2.69(0.68)$ & 0.016 & $2.79(0.75)$ & $2.79(0.74)$ & 0.839 \\
\hline Serum uric acid ( $\mu \mathrm{mol} / \mathrm{L})$ & 325.71 (81.72) & 332.94 (73.72) & $293.72(71.12)$ & $<0.001$ & $369.41(78.22)$ & $331.10(80.78)$ & $<0.001$ \\
\hline Fasting blood glucose (mmol/L) & $5.21(1.21)$ & $5.53(1.34)$ & $4.99(1.03)$ & $<0.001$ & $5.57(1.50)$ & $5.12(0.94)$ & $<0.001$ \\
\hline Vitamin D (nmol/L) & $61.21(21.64)$ & $60.95(18.54)$ & $61.32(22.97)$ & 0.844 & $59.03(19.46)$ & $63.56(22.09)$ & $<0.001$ \\
\hline
\end{tabular}

Data are expressed as mean (SD)

$H D L-C$ high-density lipoprotein cholesterol, $L D L-C$ low-density lipoprotein cholesterol, NAFLD nonalcoholic fatty liver disease 
Table 2 Association of vitamin D quartiles with prevalence of NAFLD in lean and obese participants

\begin{tabular}{|c|c|c|c|c|c|c|c|c|c|c|c|c|}
\hline \multirow{2}{*}{$\begin{array}{l}\text { VD } \\
\text { quartiles }\end{array}$} & \multicolumn{6}{|c|}{ Lean participants } & \multicolumn{6}{|c|}{ Obese participants } \\
\hline & Total & NAFLD & PR\% & PR & $x^{2}$ & $P$ value & Total & NAFLD & PR\% & PR & $x^{2}$ & $P$ value \\
\hline Quartile 1 & 327 & 37 & 11.31 & 0.95 & & & 306 & 173 & 56.54 & 1.27 & & \\
\hline Quartile 2 & 292 & 38 & 13.01 & 1.09 & & & 343 & 205 & 59.77 & 1.34 & & \\
\hline Quartile 3 & 306 & 50 & 16.34 & 1.37 & & & 326 & 170 & 52.15 & 1.17 & & \\
\hline Quartile 4 & 319 & 38 & 11.91 & 1.00 & 4.133 & 0.247 & 319 & 142 & 44.51 & 1.00 & 17.118 & $<0.01$ \\
\hline
\end{tabular}

Participants were classified into quartiles according to their serum vitamin D levels: quartile $1,<45.5 \mathrm{nmol} / \mathrm{L} ;$ quartile $2,45.5-59.5 \mathrm{nmol} / \mathrm{L} ;$ quartile $3,59.6-74.2$ $\mathrm{nmol} / \mathrm{L}$; and quartile $4, \geq 74.3 \mathrm{nmol} / \mathrm{L}$

$V D$ vitamin $D, P R \%$ prevalence rate, $P R$ prevalence ratio

\section{Association of serum vitamin D level with risk of NAFLD}

We performed multiple logistic regression analyses to explore the risk factors of NAFLD in lean and obese participants. We found that male sex, high BMI and waist circumference, high serum levels of alanine aminotransferase, triglyceride, LDL-cholesterol, uric acid, and fasting blood glucose, and low serum levels of HDLcholesterol were correlated with increased risks of NAFL $\mathrm{D}$ in both lean and obese participants (Table 4). We also found that serum vitamin $\mathrm{D}$ concentration was a protection factor associated with the risk of NAFLD in obese participants, with an adjusted odds ratio (OR) (95\% CI) of 0.987 (0.981-0.993). However, serum vitamin D concentration was not associated with the risk of NAFLD in lean participants (Table 4).

We divided all of the participants into the categories of central obesity and non-central obesity according to their waist circumference. We found that, in the central obesity group, vitamin $\mathrm{D}$ concentration was a protective factor for NAFLD with an adjusted OR (95\% CI) of 0.994 (0.989-0.999), but this was not the case in the non-central obesity group (Supplementary Table S1). Moreover, we found that regardless of metabolic syndrome status, serum vitamin D concentration was a protective factor for NAFLD in obese participants but not in lean participants (Supplementary Table S2).

We also analyzed the correlation between vitamin D quartiles and the risk of NAFLD (Table 5). Among obese participants, compared with participants in the fourth quartile, participants with serum vitamin D levels in the first, second, and third quartiles all showed increased risk of NAFLD, with the adjusted OR (95\% CI) of 1.973 (1.359-2.865), $1.964(1.371-2.815)$, and 1.420 (0.992-
2.033), respectively. However, the risk of NAFLD was comparable among lean participants with serum vitamin $\mathrm{D}$ levels in all of the quartiles (Table 5). Similar results were observed by dividing all of the participants into central obesity and non-central obesity categories according to their waist circumference (Supplementary Table S3).

We further analyzed the correlation between vitamin $\mathrm{D}$ adequacy status and risk of NAFLD (Table 6). Among obese participants, those with vitamin D deficiency showed an increased risk of NAFLD compared with those with vitamin D sufficiency, with an adjusted OR (95\% CI) of 2.076 (1.462-2.950). However, among lean participants, vitamin D deficiency was not associated with risk of NAFLD in adjusted models (Table 6). These results showed that decreased serum vitamin D concentration was associated with an increased risk of NAFLD in obese but not lean participants.

\section{Discussion}

In this study, we explored the correlation between serum vitamin D concentration and NAFLD in Chinese adults. We found that serum vitamin D concentrations of obese NAFLD patients were lower than those of obese controls without NAFLD. We also found that serum vitamin D concentration was negatively correlated with the prevalence of NAFLD in obese but not lean participants. Our further analysis showed that decreased serum vitamin D concentration and vitamin D deficiency were associated with an increased risk of NAFLD in obese but not lean participants. These findings suggested a significant correlation between serum vitamin $\mathrm{D}$ concentration and NAFLD in obese but not lean participants.

Table 3 Association of vitamin D sufficiency with prevalence of NAFLD in lean and obese participants

\begin{tabular}{|c|c|c|c|c|c|c|c|c|c|c|c|c|}
\hline \multirow{2}{*}{$\begin{array}{l}\text { VD } \\
\text { classification }\end{array}$} & \multicolumn{6}{|c|}{ Lean participants } & \multicolumn{6}{|c|}{ Obese participants } \\
\hline & Total & NAFLD & PR\% & PR & $x^{2}$ & $P$-value & Total & NAFLD & PR\% & PR & $x^{2}$ & $P$ value \\
\hline VD deficiency & 422 & 47 & 11.14 & 1.02 & & & 408 & 235 & 57.60 & 1.33 & & \\
\hline VD insufficiency & 519 & 83 & 15.99 & 1.47 & & & 576 & 321 & 55.73 & 1.29 & & \\
\hline VD sufficiency & 303 & 33 & 10.89 & 1.00 & 6.539 & 0.038 & 310 & 134 & 43.23 & 1.00 & 17.034 & $<0.001$ \\
\hline
\end{tabular}

$V D$ vitamine $D, P R \%$ prevalence rate, $P R$ prevalence ratio

Participants were classified into three groups according to their serum VD levels: VD deficiency, $<50.0 \mathrm{nmol} / \mathrm{L} ; \mathrm{VD}$ insufficiency, $50.0-74.9 \mathrm{nmol} / \mathrm{L} ;$ and VD sufficiency, $\geq 75.0 \mathrm{nmol} / \mathrm{L}$. 
Table 4 Logistic regression analysis for factors associated with risk of NAFLD in lean and obese participants

\begin{tabular}{|c|c|c|c|c|c|c|}
\hline \multirow[t]{2}{*}{ Variables } & \multicolumn{3}{|c|}{ Lean participants } & \multicolumn{3}{|c|}{ Obese participants } \\
\hline & Wald $x^{2}$ & OR $(95 \% \mathrm{Cl})$ & $P$ value & Wald $x^{2}$ & OR $(95 \% \mathrm{Cl})$ & $P$ value \\
\hline Male gender & 10.789 & $2.234(1.383-3.608)$ & 0.001 & 5.315 & $1.494(1.062-2.101)$ & 0.021 \\
\hline Body mass index $\left(\mathrm{kg} / \mathrm{m}^{2}\right)$ & 13.163 & $1.439(1.182-1.751)$ & $<0.001$ & 13.794 & $1.192(1.086-1.307)$ & $<0.001$ \\
\hline Waist circumference (cm) & 9.856 & $1.074(1.027-1.122)$ & 0.002 & 11.344 & $1.052(1.021-1.084)$ & 0.001 \\
\hline Alanine aminotransferase (U/L) & 11.112 & $1.019(1.008-1.030)$ & 0.001 & 27.934 & $1.026(1.016-1.036)$ & $<0.001$ \\
\hline Triglyceride (mmol/L) & 15.537 & $1.460(1.210-1.762)$ & $<0.001$ & 12.495 & $1.302(1.125-1.507)$ & $<0.001$ \\
\hline HDL-cholesterol (mmol/L) & 11.076 & $0.271(0.125-0.584)$ & 0.001 & 19.940 & $0.271(0.153-0.480)$ & $<0.001$ \\
\hline LDL-cholesterol (mmol/L) & 8.583 & $1.469(1.136-1.899)$ & 0.003 & 4.322 & $1.205(1.011-1.437)$ & 0.038 \\
\hline Serum uric acid ( $\mu \mathrm{mol} / \mathrm{L})$ & 9.342 & $1.005(1.002-1.008)$ & 0.002 & 13.417 & $1.004(1.002-1.006)$ & $<0.001$ \\
\hline Fasting blood glucose (mmol/L) & 11.160 & $1.251(1.097-1.427)$ & 0.001 & 15.639 & $1.274(1.130-1.436)$ & $<0.001$ \\
\hline Vitamin D (nmol/L) & - & - & - & 18.017 & $0.987(0.981-0.993)$ & $<0.001$ \\
\hline
\end{tabular}

OR odds ratio, $C I$ confidence interval, $H D L$-cholesterol high-density lipoprotein cholesterol, $L D L-C$ low-density lipoprotein cholesterol

Several studies have reported that there is a significant correlation between serum vitamin D concentration and NAFLD [31, 32], and this was confirmed by a meta-analysis including 12,794 participants of 17 studies [33]. Moreover, low serum vitamin D concentration is related to greater severity of hepatic steatosis and necrotizing inflammation in both children and adults [34, 35]. Preclinical investigations found that vitamin $\mathrm{D}$ supplementation significantly improved liver steatosis in high-fat diet-fed mice [22]. In addition, both our research team and others found that vitamin D receptor (VDR) is upregulated in the steatotic liver and may be a therapeutic target for NAFLD [22, 36]. As we know, low serum vitamin D levels are more commonly observed in obese than in lean individuals [37]. However, whether lean and obese individuals show a similar association of vitamin D with NAFLD remains speculative and should be investigated. In this study, we provided evidence that low serum vitamin D levels are associated with obese but not lean populations.

The explanation for why obese and lean individuals have inconsistent correlations between vitamin $\mathrm{D}$ and NAFLD remains unclear, although several possibilities exist. First, obesity could be a contributing factor to low vitamin D levels [38,39]. With fewer outdoor activities and thus less exposure to sunlight, obese individuals may have decreased vitamin D synthesized in the liver or percutaneously [8]. A genetic study showed that each increase in BMI will reduce serum vitamin D concentration by $1.15 \%$ [40]. Second, patients with vitamin D deficiency have higher serum levels of proinflammatory cytokines, which promote the development of NAFLD [41]. In the non-alcoholic steatohepatitis (NASH) stage, vitamin $\mathrm{D}$ deficiency can also actively regulate the synthesis of endogenous fatty acids in the liver by weakening enterohepatic circulation [42]. Third, vitamin D regulates lipid transport by binding with vitamin $\mathrm{D}$

Table 5 Association of serum vitamin D quartiles with risk of NAFLD in lean and obese participants

\begin{tabular}{|c|c|c|c|c|c|c|c|}
\hline \multirow[t]{5}{*}{ Lean } & \multirow[t]{2}{*}{ Models } & \multicolumn{4}{|c|}{ Odds ratios ( $95 \%$ confidence interval) } & \multirow[t]{2}{*}{$x^{2}$ value } & \multirow[t]{2}{*}{$P$ value } \\
\hline & & Quartile $1(n=327)$ & Quartile $2(n=292)$ & Quartile $3(n=306)$ & Quartile $4(n=319)$ & & \\
\hline & Model 1 & $0.943(0.583-1.527)$ & $1.106(0.684-1.789)$ & $1.444(0.917-2.275)$ & 1 & 4.100 & 0.251 \\
\hline & Model 2 & $1.248(0.742-2.099)$ & $1.334(0.800-2.225)$ & $1.557(0.961-2.522)$ & 1 & 3.305 & 0.347 \\
\hline & Model 3 & $1.176(0.673-2.055)$ & $1.063(0.609-1.853)$ & $1.535(0.916-2.571)$ & 1 & 3.238 & 0.356 \\
\hline \multirow[t]{5}{*}{ Obese } & Models & \multicolumn{4}{|c|}{ Odds ratios ( $95 \%$ confidence interval) } & \multirow[t]{2}{*}{$x^{2}$ value } & \multirow[t]{2}{*}{$P$ value } \\
\hline & & Quartile $1(n=306)$ & Quartile $2(n=343)$ & Quartile $3(n=326)$ & Quartile $4(n=319)$ & & \\
\hline & Model 1 & $1.621(1.182-2.224)$ & $1.852(1.360-2.521)$ & $1.358(0.996-1.852)$ & 1 & 16.980 & 0.001 \\
\hline & Model 2 & $1.941(1.368-2.753)$ & $1.963(1.404-2.746)$ & $1.508(1.080-2.105)$ & 1 & 19.461 & $<0.001$ \\
\hline & Model 3 & $1.973(1.359-2.865)$ & $1.964(1.371-2.815)$ & $1.420(0.992-2.033)$ & 1 & 17.747 & $<0.001$ \\
\hline
\end{tabular}

Model 1 was unadjusted

Model 2 was adjusted for age, gender, waist circumference and body mass index

Model 3 was further adjusted for systolic and diastolic blood pressure, alanine aminotransferase, $\gamma$-glutamyl transpeptidase, triglyceride, HDL-cholesterol, LDLcholesterol, fasting blood glucose and serum uric acid

Participants were classified into quartiles according to their serum vitamin D levels: quartile $1,<45.5 \mathrm{nmol} / \mathrm{L} ;$ quartile $2,45.5-59.5 \mathrm{nmol} / \mathrm{L} ;$ quartile $3,59.6-74.2$ $\mathrm{nmol} / \mathrm{L}$; and quartile $4, \geq 74.3 \mathrm{nmol} / \mathrm{L}$ 
Table 6 Association of vitamin D sufficiency status with risk of NAFLD in lean and obese participants

\begin{tabular}{|c|c|c|c|c|c|c|}
\hline \multirow[t]{5}{*}{ Lean } & \multirow[t]{2}{*}{ Models } & \multicolumn{3}{|c|}{ Odds ratios ( $95 \%$ confidence interval) } & \multirow[t]{2}{*}{$x^{2}$ value } & \multirow[t]{2}{*}{$P$ value } \\
\hline & & VD deficiency $(n=422)$ & VD insufficiency $(n=519)$ & VD sufficiency $(n=303)$ & & \\
\hline & Model 1 & $1.025(0.640-1.644)$ & $1.558(1.012-2.397)$ & 1 & 6.474 & 0.039 \\
\hline & Model 2 & $1.335(0.803-2.221)$ & $1.726(1.091-2.730)$ & 1 & 5.736 & 0.057 \\
\hline & Model 3 & $1.192(0.693-2.050)$ & $1.602(0.982-2.612)$ & 1 & 4.145 & 0.126 \\
\hline \multirow[t]{5}{*}{ Obese } & Models & \multicolumn{3}{|c|}{ Odds ratios ( $95 \%$ confidence interval) } & \multirow[t]{2}{*}{$x^{2}$ value } & \multirow[t]{2}{*}{$P$ value } \\
\hline & & VD deficiency $(n=408)$ & VD insufficiency $(n=576)$ & VD sufficiency $(n=310)$ & & \\
\hline & Model 1 & $1.784(1.324-2.405)$ & $1.653(1.252-2.184)$ & 1 & 16.853 & $<0.001$ \\
\hline & Model 2 & $2.055(1.479-2.854)$ & $1.792(1.325-2.423)$ & 1 & 20.578 & $<0.001$ \\
\hline & Model 3 & $2.076(1.462-2.950)$ & $1.730(1.252-2.390)$ & 1 & 17.737 & $<0.001$ \\
\hline
\end{tabular}

Model 1 was unadjusted

Model 2 was adjusted for age, gender, waist circumference and body mass index

Model 3 was further adjusted for systolic and diastolic blood pressure, alanine aminotransferase, $\gamma$-glutamyl transpeptidase, triglyceride, HDL-cholesterol, LDLcholesterol, fasting blood glucose and serum uric acid

Participants were classified into three groups according to their serum VD levels: VD deficiency, $<50.0 \mathrm{nmol} / \mathrm{L} ; \mathrm{VD}$ insufficiency, 50-74.9 nmol/L; and VD sufficiency, $\geq 75.0 \mathrm{nmol} / \mathrm{L}$.

receptor and activating Hepatocyte nuclear factor $4 \alpha$ (HNF4 $\alpha$ ) [22]. Therefore, under vitamin D deficiency conditions, the flow of free fatty acids (FFAs) in the blood increases, and fat deposition into hepatocytes is accelerated, contributing to the progress of NAFLD [43]. Further research is needed to clarify these possibilities.

Recently, researchers have subdivided NAFLD into obese and lean subtypes, and many studies have focused on lean NAFLD [44-46]. Vitamin D concentration is closely related to NAFLD, and vitamin D deficiency is considered a risk factor for NAFLD [32, 43]. However, it was not clear whether vitamin D concentration was also associated with lean NAFLD. In this study, we found that low vitamin D concentration is associated with obese but not lean NAFLD. Based on the cross-sectional study, we hypothesized that the vitamin D concentration may be an important predictor of NAFLD in the obese but not lean population.

Some limitations of this study should be acknowledged. First, our NAFLD was diagnosed based on ultrasound. Although ultrasound NAFLD diagnosis has been widely used clinically as a screening method for hepatic steatosis, it is still insufficient to detect mild steatosis, and it cannot replace the gold standard for liver biopsy. The correlation between vitamin D levels and NAFLD histological severity was not explored in this study. Second, this is a single-center cross-sectional study. Our sample size may be insufficient to represent the entire Chinese adult population, and further multi-center cohort studies are needed. Third, the BMI classification criteria applied in this study are limited to East Asian people, so our findings may not be generalizable to other ethnic populations. Fourth, our study is a cross-sectional study, and further prospective studies are needed to analyze the causal relationship between vitamin D deficiency and the onset of NAFLD.

\section{Conclusions}

Our cross-sectional study provides evidence that there is a significant correlation between serum vitamin D concentration and NAFLD in obese but not lean participants. Further research is needed to explore the complicated relationships and possible mechanisms between obesity, vitamin D level, and NAFLD.

\section{Abbreviations}

NAFLD: Non-alcoholic fatty liver disease; BMI: Body mass index; ECLIA: Electro-chemiluminescence immunoassay; IQR: Interquartile range; VDR: Vitamin D receptor; NASH: Non-alcoholic steatohepatitis; PPAR$\gamma$ : Peroxisome proliferator-activated receptor $\gamma_{\text {; }}$ FFA: Free fatty acid

\section{Supplementary Information}

The online version contains supplementary material available at https://doi. org/10.1186/s12937-021-00690-9.

Additional file 1: Supplementary Table S1. Logistical regression analysis for factors with risk of NAFLD in lean and central obese participants

Additional file 2: Supplementary Table S2. Association of serum vitamin D concentrations with risk of NAFLD in lean and obese participants with or without metabolic syndrome

Additional file 3: Supplementary Table S3. Association of serum vitamin D quartiles with risk of NAFLD in lean and central obese participants

\section{Acknowledgments}

We thank LetPub (www.letpub.com) for its linguistic assistance during the preparation of this manuscript.

\section{Authors' contributions}

Qinqiu Wang (QQW) and Xiaoying Shi (XYS) collected and analyzed participant data, and completed the manuscript writing. Jinghua Wang (JHW) and Juanwen Zhang (JWZ) did data collection and interpretation. Chengfu Xu (CFX) did the study design and implementation, manuscript drafting, and critical revision of the manuscript for important intellectual content. Qinqiu Wang (QQW) and Xiaoying Shi (XYS) contributed equally to this study. All authors read and approved the final manuscript. 


\section{Funding}

This work was supported by the National Natural Science Foundation of China (Nos. 81770573 and 81722009), Key Research and Development Program of Zhejiang Province (No. 2020C03033).

\section{Availability of data and materials}

The data that support the findings of this study are available from the First Affiliated Hospital, Zhejiang University School of Medicine but restrictions apply to the availability of these data, which were used under license for the current study, and so are not publicly available. Data are however available from the authors upon reasonable request and with permission of the First Affiliated Hospital, Zhejiang University School of Medicine.

\section{Declarations}

\section{Ethics approval and consent to participate}

The study was approved by the Ethical Committee of the First Affiliated Hospital, Zhejiang University School of Medicine (IIT20200707A).

\section{Consent for publication}

Not applicable.

\section{Competing interests}

The authors declare that they have no competing interests.

\section{Author details}

'Department of Gastroenterology, the First Affiliated Hospital, Zhejiang University School of Medicine, 79 Qingchun Road, Hangzhou 310003, China. 2Department of Laboratory Medicine, the First Affiliated Hospital, Zhejiang University School of Medicine, Hangzhou 310003, China.

Received: 9 September 2020 Accepted: 25 March 2021

Published online: 01 April 2021

\section{References}

1. Yki-Järvinen $\mathrm{H}$. Non-alcoholic fatty liver disease as a cause and a consequence of metabolic syndrome. Lancet Diabetes Endocrinol. 2014; 2(11):901-10. https://doi.org/10.1016/S2213-8587(14)70032-4.

2. Zhou F, Zhou J, Wang W, Zhang XJ, Ji YX, Zhang P, et al. Unexpected rapid increase in the burden of NAFLD in China from 2008 to 2018: a systematic review and meta-analysis. Hepatology. 2019;70(4):1119-33. https://doi.org/1 $0.1002 /$ hep.30702.

3. Chalasani N, Younossi Z, Lavine JE, Charlton M, Cusi K, Rinella M, et al. The diagnosis and management of nonalcoholic fatty liver disease: practice guidance from the American Association for the Study of Liver Diseases. Hepatology. 2018;67(1):328-57. https://doi.org/10.1002/hep.29367.

4. Degasperi $\mathrm{E}$, Colombo M. Distinctive features of hepatocellular carcinoma in non-alcoholic fatty liver disease. Lancet Gastroenterol Hepatol. 2016;1(2): 156-64. https://doi.org/10.1016/S2468-1253(16)30018-8.

5. Hagström H, Nasr P, Ekstedt M, Hammar U, Stål P, Askling J, et al. Cardiovascular risk factors in non-alcoholic fatty liver disease. Liver Int. 2019; 39(1):197-204. https://doi.org/10.1111/liv.13973.

6. Jarvis $H$, Craig D, Barker R, Spiers G, Stow D, Anstee QM, et al. Metabolic risk factors and incident advanced liver disease in non-alcoholic fatty liver disease (NAFLD): a systematic review and meta-analysis of population-based observational studies. PLoS Med. 2020;17(4):e1003100. https://doi.org/10.13 71/journal.pmed.1003100.

7. Li H, Hu B, Wei L, Zhou L, Zhang L, Lin Y, et al. Non-alcoholic fatty liver disease is associated with stroke severity and progression of brainstem infarctions. Eur J Neurol. 2018;25(3):577-e34. https://doi.org/10.1111/ene.13 556.

8. Adams LA, Anstee QM, Tilg H, Targher G. Non-alcoholic fatty liver disease and its relationship with cardiovascular disease and other extrahepatic diseases. Gut. 2017;66(6):1138-53. https://doi.org/10.1136/gutjnl-2017-313 884.

9. Younossi ZM. Non-alcoholic fatty liver disease - a global public health perspective. J Hepatol. 2019;70(3):531-44. https://doi.org/10.1016/j.jhep.201 8.10.033.

10. Polyzos SA, Kountouras J, Mantzoros CS. Obesity and nonalcoholic fatty liver disease: from pathophysiology to therapeutics. Metabolism. 2019;92:82-97. https://doi.org/10.1016/j.metabol.2018.11.014.
11. Zou B, Yeo YH, Nguyen VH, Cheung R, Ingelsson E, Nguyen MH. Prevalence, characteristics and mortality outcomes of obese, nonobese and lean NAFLD in the United States, 1999-2016. J Intern Med. 2020;288(1):139-51. https:// doi.org/10.1111/joim.13069.

12. Fan JG, Kim SU, Wong WW. New trends on obesity and NAFLD in Asia. J Hepatol. 2017:67(4):862-73. https://doi.org/10.1016/j.jhep.2017.06.003.

13. Xu C, Yu C, Ma H, Xu L, Miao M, Li Y. Prevalence and risk factors for the development of nonalcoholic fatty liver disease in a nonobese Chinese population: the Zhejiang Zhenhai study. Am J Gastroenterol. 2013;108(8): 1299-304. https://doi.org/10.1038/ajg.2013.104.

14. Hagström H, Nasr P, Ekstedt M, Hammar U, Stål P, Hultcrantz R, et al. Risk for development of severe liver disease in lean patients with nonalcoholic fatty liver disease: a long-term follow-up study. Hepatol Commun. 2018;2(1):4857. https://doi.org/10.1002/hep4.1124.

15. Zeng J, Yang RX, Sun C, Pan Q, Zhang RN, Chen GY, et al. Prevalence, clinical characteristics, risk factors, and indicators for lean Chinese adults with nonalcoholic fatty liver disease. World J Gastroenterol. 2020;26(15): 1792-804. https://doi.org/10.3748/wjg.v26.115.1792.

16. Liu S, Liu Y, Wan B, Zhang H, Wu S, Zhu Z, et al. Association between vitamin D status and non-alcoholic fatty liver disease: a population-based study. J Nutr Sci Vitaminol. 2019;65(4):303-8. https://doi.org/10.3177/jnsv. 65.303.

17. Zhai HL, Wang NJ, Han B, Li Q, Chen Y, Zhu CF, et al. Low vitamin D levels and non-alcoholic fatty liver disease, evidence for their independent association in men in East China: a cross-sectional study (survey on prevalence in East China for metabolic diseases and risk factors (SPECTChina)). Brit J Nutr. 2016;115(8):1352-9. https://doi.org/10.1017/S000711451 6000386.

18. Bhatt SP, Nigam P, Misra A, Guleria R, Qadar Pasha MA. Independent associations of low 25 hydroxy vitamin $D$ and high parathyroid hormonal levels with nonalcoholic fatty liver disease in Asian Indians residing in North India. Atherosclerosis. 2013;230(1):157-63. https://doi.org/10.1016/j.a therosclerosis.2013.07.006.

19. Ha Y, Hwang SG, Rim KS. The association between vitamin D insufficiency and nonalcoholic fatty liver disease: a population-based study. Nutrients. 2017:9(8):806.

20. Hao YP, Ma XJ, Luo YQ, Ni J, Dou JX, Hu YQ, et al. Serum vitamin D is associated with non-alcoholic fatty liver disease in Chinese males with normal weight and liver enzymes. Acta Pharmacol Sin. 2014;35(9):1150-6. https://doi.org/10.1038/aps.2014.48.

21. Cordeiro A, Pereira S, Saboya CJ, Ramalho A. Relationship between nonalcoholic fatty liver disease and vitamin D nutritional status in extreme obesity. Can J Gastroenterol Hepatol. 2017;2017:9456897.

22. Zhang $H$, Shen $Z$, Lin $Y$, Zhang J, Zhang $Y$, Liu P, et al. Vitamin D receptor targets hepatocyte nuclear factor $4 a$ and mediates protective effects of vitamin D in nonalcoholic fatty liver disease. J Biol Chem. 2020;295(12): 3891-905. https://doi.org/10.1074/jbc.RA119.011487.

23. Lorvand Amiri H, Agah S, Tolouei Azar J, Hosseini S, Shidfar F, Mousavi SN Effect of daily calcitriol supplementation with and without calcium on disease regression in non-alcoholic fatty liver patients following an energyrestricted diet: randomized, controlled, double-blind trial. Clin Nutr. 2017; 36(6):1490-7. https://doi.org/10.1016/j.clnu.2016.09.020.

24. Papapostoli I, Lammert F, Stokes CS. Effect of short-term vitamin D correction on hepatic Steatosis as quantified by controlled attenuation parameter (CAP). J Gastrointestin Liver Dis. 2016;25(2):175-81. https://doi. org/10.15403/jgld.2014.1121.252.cap.

25. Lu ZY, Cen C, Shao Z, Chen XH, Xu CF, Li YM. Association between serum a-L-fucosidase and non-alcoholic fatty liver disease: cross-sectional study. World J Gastroenterol. 2016;22(5):1884-90. https://doi.org/10.3748/wjg.v22. i5.1884.

26. Lu Z, Ma H, Xu C, Shao Z, Cen C, Li Y. Serum Sialic acid level is significantly associated with nonalcoholic fatty liver disease in a nonobese Chinese population: a cross-sectional study. Biomed Res Int. 2016;2016:5921589.

27. WHO Expert Consultation. Appropriate body-mass index for Asian populations and its implications for policy and intervention strategies. Lancet. 2004;363(9403):157-63.

28. Holick M. Vitamin D deficiency. New Engl J Med. 2007;357(3):266-81. https://doi.org/10.1056/NEJMra070553.

29. Alberti KG, Zimmet $P$, Shaw J. Metabolic syndrome--a new world-wide definition. A consensus statement from the international diabetes 
federation. Diabet Med. 2006;23(5):469-80. https://doi.org/10.1111/j.1464-54 91.2006.01858.x

30. Fan JG, Wei L, Zhuang H. Guidelines of prevention and treatment of nonalcoholic fatty liver disease (2018, China). J Dig Dis. 2019;20(4):163-73. https://doi.org/10.1111/1751-2980.12685.

31. Rhee EJ, Kim MK, Park SE, Park CY, Baek KH, Lee WY, et al. High serum vitamin $\mathrm{D}$ levels reduce the risk for nonalcoholic fatty liver disease in healthy men independent of metabolic syndrome. Endocr J. 2013;60(6):74352. https://doi.org/10.1507/endocrj.EJ12-0387.

32. Jablonski KL, Jovanovich A, Holmen J, Targher G, McFann K, Kendrick J, et al. Low 25 -hydroxyvitamin $D$ level is independently associated with nonalcoholic fatty liver disease. Nutr Metab Cardiovasc Dis. 2013;23(8):792-8. https://doi.org/10.1016/j.numecd.2012.12.006.

33. Eliades M, Spyrou E, Agrawal N, Lazo M, Brancati FL, Potter JJ, et al. Metaanalysis: vitamin $\mathrm{D}$ and non-alcoholic fatty liver disease. Aliment Pharmacol Ther. 2013;38(3):246-54. https://doi.org/10.1111/apt.12377.

34. Nobili V, Giorgio V, Liccardo D, Bedogni G, Morino G, Alisi A, et al. Vitamin D levels and liver histological alterations in children with nonalcoholic fatty liver disease. Eur J Endocrinol. 2014;170(4):547-53. https://doi.org/10.1530/ EJE-13-0609.

35. Targher G, Bertolini L, Scala L, Cigolini M, Zenari L, Falezza G, et al. Associations between serum 25-hydroxyvitamin D3 concentrations and liver histology in patients with non-alcoholic fatty liver disease. Nutr Metab Cardiovasc Dis. 2007;17(7):517-24. https://doi.org/10.1016/..numecd.2006.04. 002 .

36. Keane JT, Elangovan H, Stokes RA, Gunton JE. Vitamin D and the livercorrelation or cause? Nutrients. 2018;10(4):496. https://doi.org/10.3390/nu1 0040496.

37. Pereira-Santos M, Costa PR, Assis AM, Santos CA, Santos DB. Obesity and vitamin D deficiency: a systematic review and meta-analysis. Obes Rev. 2015;16(4):341-9. https://doi.org/10.1111/obr.12239.

38. Holick MF, Binkley NC, Bischoff-Ferrari HA, Gordon CM, Hanley DA, Heaney RP, et al. Evaluation, treatment, and prevention of vitamin D deficiency: an Endocrine Society clinical practice guideline. J Clin Endocrinol Metab. 2011; 96(7):1911-30. https://doi.org/10.1210/jc.2011-0385.

39. Kwok RM, Torres DM, Harrison SA. Vitamin D and nonalcoholic fatty liver disease (NAFLD): is it more than just an association? Hepatology. 2013;58(3): 1166-74. https://doi.org/10.1002/hep.26390.

40. Vimaleswaran KS, Berry DJ, Lu C, Tikkanen E, Pilz S, Hiraki LT, et al. Causal relationship between obesity and vitamin D status: bi-directional Mendelian randomization analysis of multiple cohorts. PLoS Med. 2013;10(2):e1001383. https://doi.org/10.1371/journal.pmed.1001383.

41. Chakraborty A, Choudhury A, Saha A. Development of non-alcoholic fatty liver disease (NAFLD) in young obese tribal subjects of Tripura: link between low $25(\mathrm{OH})$ vitamin-D levels and immune modulators. J Assoc Physicians India. 2019;67(8):52-6.

42. Kong M, Zhu L, Bai L, Zhang X, Chen Y, Liu S, et al. Vitamin D deficiency promotes nonalcoholic steatohepatitis through impaired enterohepatic circulation in animal model. Am J Physiol Gastrointest Liver Physiol. 2014; 307(9):G883-93. https://doi.org/10.1152/ajpgi.00427.2013.

43. Barchetta I, Angelico F, Del Ben M, Baroni MG, Pozzilli P, Morini S, et al. Strong association between non alcoholic fatty liver disease (NAFLD) and low $25(\mathrm{OH})$ vitamin D levels in an adult population with normal serum liver enzymes. BMC Med. 2011;9(1):85. https://doi.org/10.1186/1741-7015-9-85.

44. Akyuz U, Yesil A, Yilmaz Y. Characterization of lean patients with nonalcoholic fatty liver disease: potential role of high hemoglobin levels. Scand J Gastroenterol. 2015;50(3):341-6. https://doi.org/10.3109/00365521.2 014.983160

45. Younossi ZM, Stepanova M, Negro F, Hallaji S, Younossi Y, Lam B, et al. Nonalcoholic fatty liver disease in lean individuals in the United States. Medicine. 2012:91(6):319-27. https://doi.org/10.1097/MD.0b013e3182779d49.

46. Wang AY, Dhaliwal J, Mouzaki M. Lean non-alcoholic fatty liver disease. Clin Nutr. 2019;38(3):975-81. https://doi.org/10.1016/j.clnu.2018.08.008.

\section{Publisher's Note}

Springer Nature remains neutral with regard to jurisdictional claims in published maps and institutional affiliations.

\section{Ready to submit your research? Choose BMC and benefit from:}

- fast, convenient online submission

- thorough peer review by experienced researchers in your field

- rapid publication on acceptance

- support for research data, including large and complex data types

- gold Open Access which fosters wider collaboration and increased citations

- maximum visibility for your research: over $100 \mathrm{M}$ website views per year

At BMC, research is always in progress.

Learn more biomedcentral.com/submissions 